\title{
EVALUATION OF INJECTION MOULDED NATURAL FIBRE- POLYOLEFIN FOR POTENTIAL IN AUTOMOTIVE APPLICATIONS
}

\author{
James Thomason ${ }^{1 *}$, José Luis Rudeiros-Fernández ${ }^{2}$ \\ ${ }^{1,2}$ Department of Mechanical and Aerospace Engineering, University of Strathclyde, Glasgow, United Kingdom
}

\begin{abstract}
This paper presents a study on the measurements of the interfacial adhesion of coir fibre with various polyolefin matrices along with the mechanical properties of their related injection moulded composites. Fibre-matrix adhesion, including the effect of coupling agent, was characterised using the fibre pull-out method. The addition of coupling agent significantly increased the interfacial shear strength of coir fibre polypropylene. Results are also presented from tensile and impact testing of coir reinforced polyolefin composites. The results show that the coupling agent increases composite tensile strength and unnotched impact strength.
\end{abstract}

\section{INTRODUCTION}

The automotive industry is increasingly implementing light-weighting strategies in the design of automotive components in order to reduce carbon emissions over vehicle lifetime. In this respect, the use of fibre and filler reinforced thermoplastic composites have played a major role. It is thought that natural fibres may offer a viable replacement as a renewable and environmentally friendly reinforcement with an overall reduced carbon footprint. It has been reported that they may have the potential to compete with mineral fibres and fillers in certain areas (Bledzki, 1999). However, it has also been shown that natural fibre composites often have significantly lower mechanical performance in comparison to mineral fibre composites (Thomason, 2009). In particular their impact resistance may be holding back the large scale implementation of natural fibre compounds in many applications (Thomason, 2018). It is thought that optimization of the fibre-matrix interfacial adhesion is essential to successfully improve the mechanical performance of natural fibre reinforced thermoplastic compounds. This paper presents a study of single fibre pull-out measurements of the interfacial shear strength (IFSS) of coir fibre with various polyolefin matrices along with the mechanical properties of their injection moulded composites. Results will be presented from tensile and impact testing for characterisation of composite modulus, strength and impact strength. The influence of adhesion on the performance of injection moulded composites will be discussed.

\section{RESULTS AND CONCLUSIONS}

The coir fibre and polymers used for this study was provided by SABIC. The matrixes used for composites and pull-out testing were homopolymer PP 579S, copolymer PP 513MNK10, and LDPE 1922SF. Maleic anhydride grafted polypropylene ExxelorTM PO 1020 (MAPP) was used as coupling agent. The effect of MAPP on the interfacial properties of coir-PP samples was investigated for $0,3,5,10$, and $100 \mathrm{wt} \%$ MAPP content. In the case of LDPE maleic anhydride modified high density polyethylene (MAPE) Polybond ${ }^{\circledR} 3029$ was used at 5 wt $\%$ content. The results from the IFSS tests are shown in Fig. 1. It can be seen that maleated polymer coupling agent increases the fibre-matrix interaction significantly. The tensile testing results in Fig. 2 indicate that the addition of the coupling agent also results in a significant increase in the tensile strength of the coir-polyolefin composites. 


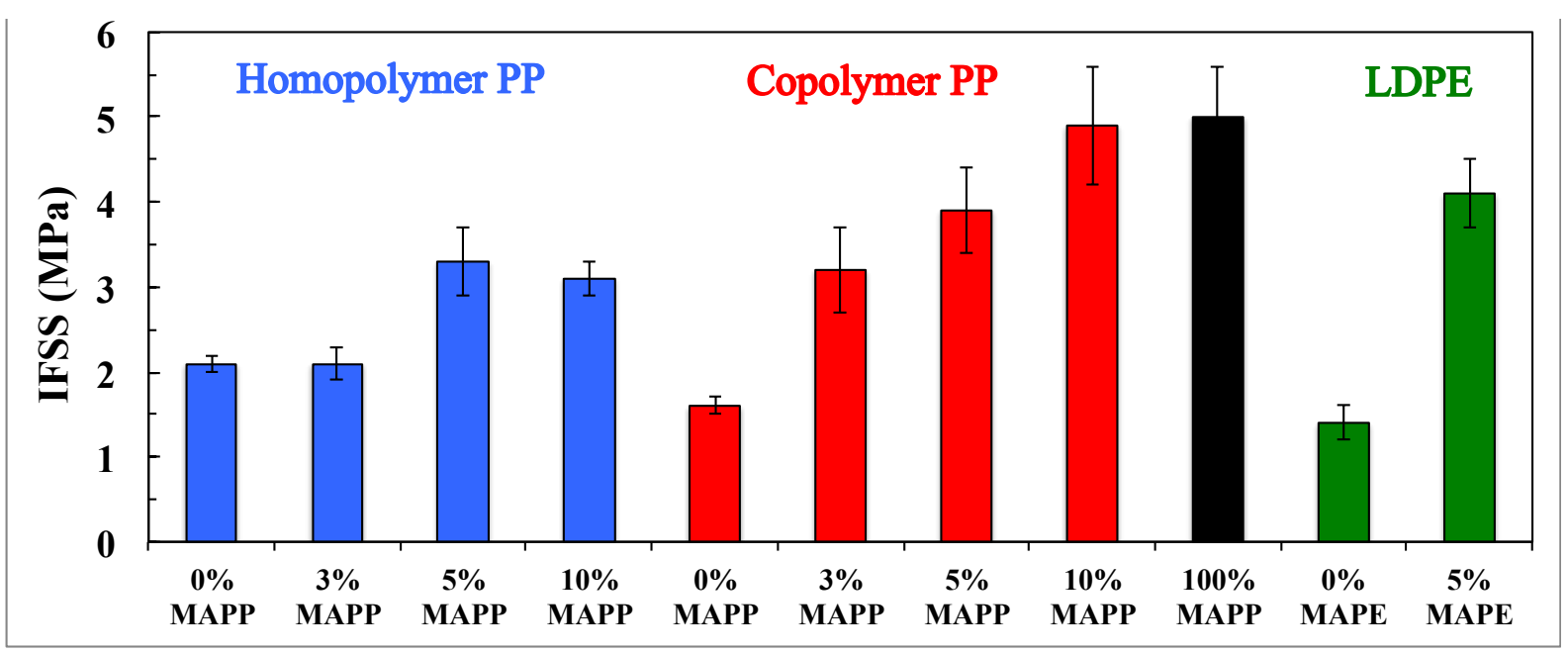

Fig.1 IFSS test results

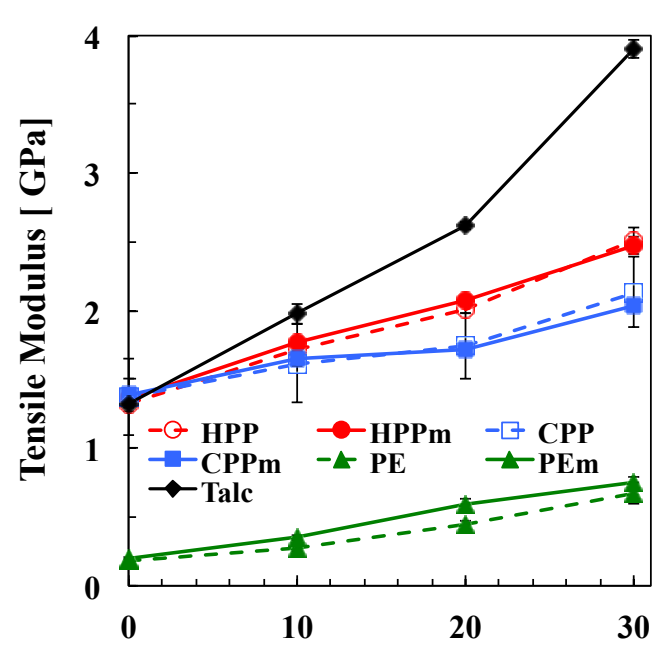

Fibre content [wt \%]

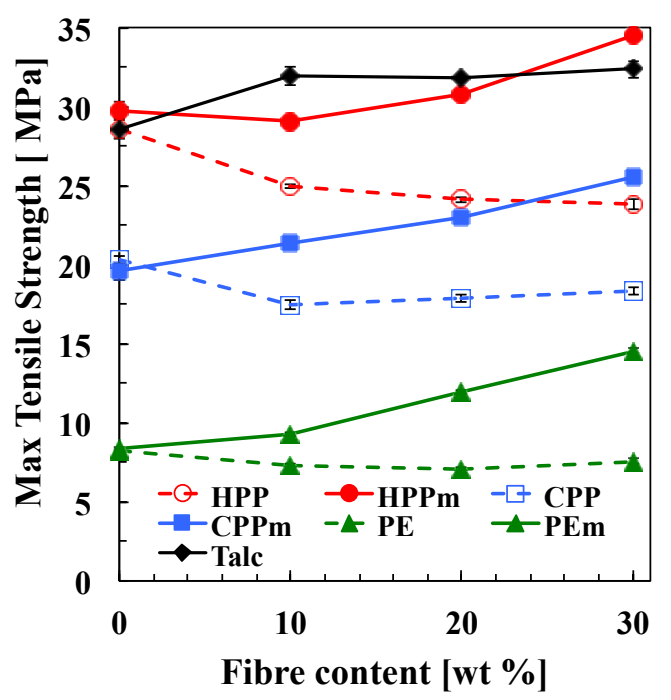

Fibre content [wt \%]

Fig.2 Tensile test results

\section{ACKNOWLEDGMENTS}

The authors gratefully acknowledge the financial support of SABIC Petrochemicals B.V. and the EPSRC Doctoral Training Grant scheme.

\section{REFERENCES}

Bledzki AK, Gassan J. Composites reinforced with cellulose based fibres. Prog Polym Sci, 1999, 24, 221-74.

Thomason JL. Why are natural fibres failing to deliver on composite performance? Proceedings of the ICCM17, 2009, Edinburgh UK.

Thomason JL, Rudeiros-Fernández JL. A review of the impact performance of natural fibre thermoplastic composites. Frontiers in Materials, 2018. 